\title{
Article \\ Effect of Nozzle Type and Adjuvants on Spray Coverage on Apple Leaves
}

\author{
Ryszard Hołownicki *(D), Grzegorz Doruchowski (D, Waldemar Świechowski, Paweł Konopacki (D) and Artur Godyń
}

The National Institute of Horticultural Research, 96-100 Skierniewice, Poland; Grzegorz.Doruchowski@inhort.pl (G.D.); Waldemar.Swiechowski@inhort.pl (W.Ś.); Pawel.Konopacki@inhort.pl (P.K.); Artur.Godyn@inhort.pl (A.G.)

* Correspondence: Ryszard.Holownicki@inhort.pl; Tel.: +48-508-000-218

Citation: Hołownicki, R.; Doruchowski, G.; Świechowski, W.; Konopacki, P.; Godyń, A. Effect of Nozzle Type and Adjuvants on Spray Coverage on Apple Leaves. Agronomy 2021, 11, 1790. https://doi.org/ 10.3390/agronomy11091790

Academic Editor: Antonio Rodríguez-Lizana

Received: 17 August 2021

Accepted: 4 September 2021

Published: 7 September 2021

Publisher's Note: MDPI stays neutral with regard to jurisdictional claims in published maps and institutional affiliations.

Copyright: (c) 2021 by the authors. Licensee MDPI, Basel, Switzerland. This article is an open access article distributed under the terms and conditions of the Creative Commons Attribution (CC BY) license (https:/ / creativecommons.org/licenses/by/ $4.0 /)$.
Abstract: Three non-ionic adjuvants, Agral, Silwet, and Greemax, at three concentrations, were applied on apple leaves with the use of hollow cone nozzles (TR) and air-induction nozzles (ID) to verify the assumption that adjuvants may improve spray coverage obtained by coarse droplets, and thereby ensure both satisfactory application quality and an environmental advantage. Spray coverage and droplet density were measured on both sides of the leaves. The adjuvants enhanced the spray coverage when applied at a certain concentration level. In general, the adjuvant coverage produced by the ID nozzles equaled the pure water coverage produced by the TR nozzles, thereby showing the adjuvants' potential to compensate for the lower spray coverage usually obtained by coarse spray. A higher spray coverage was obtained on the lower side of leaves, which is discussed in terms of leaf surface properties. In the experiment with the mixture of Silwet and the fungicide Delan (dithianon), the product interacted with the adjuvant, resulting in the reversed picture of spray coverage and droplet density on the upper and lower leaf sides compared to the results obtained for the adjuvant alone. The combination of coarse spray nozzles with adjuvants may reduce environmental pollution without compromising the quality of spray applications in fruit growing.

Keywords: spray application; deposition quality; surface wetting; leaf surface property; droplet density

\section{Introduction}

Pesticides are still intensively used in agriculture to protect crops and ensure the quality of products. One of the public concerns in this regard is the environmental impact of pesticides, mainly due to spray drift associated with the pesticide application [1]. Use of coarse spray nozzles to reduce the spray drift and emission of pesticides to the environment is a very common practice in fruit growing where, in modern orchards with small and open tree canopies, more than $80 \%$ of applied spray volume may be lost [2].

Previous studies showed that fine droplets usually result in a higher spray coverage and hence a better biological efficacy of treatments in favorable weather conditions than those obtained by coarse droplets, which are less prone to drift but more likely to rebound from the leaf surface [3]. The influence of droplet size on the biological efficacy of chemical protection has long been a subject of research; however, the obtained results are inconclusive. A lower biological effect of herbicides applied with coarse droplets, produced by air-inclusion nozzles, was observed in field crops $[4,5]$. The coarse spray also worsened the efficacy of insecticides and acaricides in orchard pest control [6,7]. However, coarse droplets resulted in similar disease control in orchards to that of fine droplets, produced by conventional hollow cone nozzles [8-13]. The incidents of lower biological efficacy observed for air-inclusion nozzles than for conventional hollow-cone nozzles can be explained by the poorer spray coverage and lower spray droplet density. Therefore, in general, fine spray nozzles are recommended for favorable weather conditions, whereas coarse spray nozzles are preferred in windy conditions. The concept of automatic adjustment of nozzles 
depending on the wind situation was implemented in the VarioWindSelect system [14] and EDAS [15].

To increase the efficacy of pesticides, some properties of spray solution are often modified by the addition of adjuvants. Adjuvants are used to enhance surface wetting and droplet spreading on the target; increase the product adhesion and rain fastness; modify the atomization process, and therefore reduce the driftability of droplets; or to improve the biological activity of products by enhancing the penetration of active ingredients and their uptake by plants [16-19]. Among different dedicated adjuvants, the surface-active agents, namely surfactants, that increase surface tension between a liquid and a target, improve the spray coverage and product retention on the target, and hence increase deposition efficiency of sprays [20].

By changing the physicochemical properties of the spray liquid, adjuvants influence the size of droplets generated by nozzles. In the article [3], which reviewed the effect of the spray liquid properties on drift risk, the authors reported that emulsified oils increased droplet size and reduced the fraction of fine droplets compared to water sprays when atomized by flat fan, hollow cone, or twin fluid nozzles. This was observed for vegetable oils, mineral oils, organosilicones, and water-insoluble surfactants. The esterified vegetable oil (Actirob B) and organosilicone surfactants (Silwet L-77) with pure water enabled the generation of bigger droplets than the combination of Tensiofix D03 and Break-Thru S-240. When an emulsifiable concentrate (EC) was applied, a smaller volume median diameter (VMD) of droplets and a higher drift potential (DP) was observed than for suspension concentrate formulation (SC), irrespective of any effect due to adjuvants. The increase in the DP was evidently due to the greater fraction of fine droplets [21]. Ref. [22] studied the effects of adjuvants on spray liquid properties and their impact on droplet size produced by FF 11003 nozzles. With the non-ionic wetting agent Agral, finer droplets were generated compared to those produced from water, whereas the use of organo-silicone Silwet L-77 resulted in production of coarser droplets. The first finding was confirmed by [23], and the latter by [21]. By comparison, little or no significant influence of crop oils on droplet size modification was observed [21,24]. The drift retardants reduce the spray drift by increasing the droplet size, but this increase is difficult to determine, because it largely depends on the actual properties of the spray liquid [3]. It was found that, with all conventional adjuvants, similar drift profiles are produced at distances greater than $2 \mathrm{~m}$ from the nozzles, and the changes of formulation have no practical meaning [22,25].

Although the size of the droplets is an important factor determining the spray coverage percentage, it is not the only factor, because spray volume rate and product formulation are equally important [13]. According to [26], it is not possible to predict the coverage based on the measured parameters of the surfactant. Moreover, no research data is available to predict the spray coverage based on the size of droplets produced by the nozzles on the air-assisted orchard sprayers [24]. If the physicochemical properties of spray liquids are the focus of the research, or if they may influence the results of studies, the adjuvants and formulation of pesticides in the tank-mix need to be taken into account [1,27]. The effect of each individual adjuvant in terms of droplet size depends on the nozzle, and therefore no generalized conclusions can be drawn regarding the influence of adjuvants on the spray formation [28].

The use of coarse droplets produced by air-inclusion nozzles, which could result in high spray coverage on the targets, may be a good solution for pesticide application to minimize the environmental impact without compromising the biological efficacy. Ref. [28], in a review of the research reports on the influence of adjuvants on droplet spectra, concluded that the effect was not always known. The effect of adjuvants on deposition or biological activity on plants may be different depending on the plant species. This makes the classification of adjuvants based on their function a difficult task. The multiple functionalities of adjuvants are a result of their specific physicochemical properties and the fact that a large number of them are mixtures of compounds. 
Artificial collectors, such as water sensitive paper (WSP), are commonly used for the measurements of spray coverage and droplet density [29], and for sprayer calibration, by visualizing the spray droplet distribution in the crop canopy. However, they have limitations because they do not represent the real coverage on the surface of natural plant targets. Due to dissimilar adhesion, retention, and spreading of droplets on the artificial collectors, they cannot reliably simulate the plant foliage, and thus substitute for the natural collectors. Therefore, the choice between natural or artificial collectors depends on the objectives of the research. If the spray coverage on the crop is the focus, the plant leaves are better spray collectors than Mylar, WSP, steel plate, or Petri dish samplers [30].

It is difficult to compare the results of previous studies, not only because of the large variety of the adjuvants' characteristics, but also due to differences in drop size measurement methods $[3,31]$. It was outlined that data may significantly differ when obtained using different methods [32], especially in the case of the coarse and very coarse sprays. Therefore, a reference system should be applied to compare data obtained with different measurement techniques [33]. Ref. [28] suggests relying on relative measurements based on comparisons with the water spray distribution. Due to these uncertainties, the presented research focused on assessing the relative influence of adjuvants on the spray, and did not consider the droplet size measurements.

Most of the reported studies on adjuvants were carried out in laboratories with the use of single droplet generators [34-38] or with the targets conveyed under a spray boom [20,39]. Although such methods ensure high repeatability and small measurement error, the conditions of the lab experiments do not reflect the real situation in orchards, where the spray deposition process is assisted by the air flow produced by the sprayer fan and is influenced by weather conditions.

It has been assumed that the addition of adjuvants in the spray liquid would improve spray coverage obtained by coarse droplets from the air-inclusion nozzles compared to that produced by fine droplets from conventional hollow cone nozzles. The objective of the described experiment was to test this hypothesis in real conditions, with the use of different adjuvants and different types of nozzles fitted on a conventional air-assisted orchard sprayer. Confirmation of this hypothesis would promote the use of drift-reducing nozzles, and provide fruit growers with greater confidence in efficacious pest and disease control in orchards. The upscaling of such a practice in fruit growing, where pesticides are used very intensively, would significantly reduce the risk of environmental pollution by the agrichemicals.

\section{Materials and Methods}

Two experiments took place in the Research Institute of Horticulture-INHORT, Department of Agroengineering, Skierniewice, Poland $\left(20.160556^{\circ} \mathrm{E}, 51.960512^{\circ} \mathrm{N}\right)$. In the first experiment, three adjuvants, Agral 90 (nonylphenoxy polyethoxy ethanol; Norac Concepts Inc., Guelph, ON, Canada), Silwet L-77 (heptamethyltrisiloxane; De Sangosse Ltd., Cambridge, UK), and Greemax (alpha-butyl-omega-hydroxypoly block polymer; Stallen Bio AG, Basel, Switzerland) were diluted in water with the addition of a fluorescent tracer. In the other experiment, Silwet L-77 was added to the water suspension of fungicide dithianon (Delan 700 WG, BASF, Ludwigshafen, Germany) with the addition of a fluorescent tracer. The adjuvants used in the experiments have properties of surfactants that lower surface tension between a liquid and a solid. In aqueous sprays of agrochemical treatments, they act as wetting and spreading agents that increase the retention of the spray on crops. Details on the adjuvants are given in Table 1. 
Table 1. Adjuvants used in experiments on their effect on spray coverage and droplet density on apple leaves.

\begin{tabular}{|c|c|c|}
\hline Trade Name & Active Ingredient & Concentration $[\%]$ \\
\hline \multicolumn{3}{|c|}{ EXPERIMENT I: water + fluorescent tracer Tinopal CBS-X, 1.5\% } \\
\hline Agral 90 & nonylphenoxy polyethoxy ethanol & $\begin{array}{l}0.05 \\
0.10 \\
0.15\end{array}$ \\
\hline Silwet L-77 & Heptamethyltrisiloxane & $\begin{array}{l}0.05 \\
0.10 \\
0.15\end{array}$ \\
\hline Greemax & alpha-butyl-omega-hydroxypoly block polymer & $\begin{array}{l}0.025 \\
0.050 \\
0.075\end{array}$ \\
\hline \multicolumn{3}{|c|}{$\begin{array}{c}\text { EXPERIMENT II: water suspension of fungicide Delan } 700 \mathrm{WG} * \text { (dithianon), } 0.2 \% \\
+ \text { fluorescent tracer Tinopal CBS-X, } 1.5 \%\end{array}$} \\
\hline Silwet L-77 & polyethoxylated hepatamethyl trisiloxane & $\begin{array}{l}0.05 \\
0.10 \\
0.15\end{array}$ \\
\hline
\end{tabular}

*WG—water-dispersible granulate; BASF, Germany.

The fluorescent tracer Tinopal CBS-X (Keystone, Chicago, IL, USA.) at the concentration of $1.5 \%$ was used to visualize the droplet spots on leaves for the coverage and droplet density measurements using image analysis. The tracer was highly soluble in water and visible in darkness when excited by UV radiation. In the event of an unlikely influence of the tracer on the spray solution surface tension, its concentration was kept constant to ensure equal conditions for all the treatments and allow for unbiased comparison of effects of the tested independent variables.

The experiments were performed outdoors, at times with comparable weather conditions for all treatments. The fresh leaves, immediately after picking from the apple trees of Jonagold cv., were used as spray collectors. Ten leaves for each treatment were attached by their petioles to a string horizontally stretched on a frame in such a manner that they could flutter in the air flow when sprayed with the air-assisted orchard sprayer (Figure 1). This method of leaf attachment aimed to provide as equal and reproducible conditions as possible for all treatments to ensure a similar behavior of the leaves in the air flow at the same distance of the leaves from the nozzles. Hence, this enabled the acquisition of the most repeatable spray coverage results within the specific treatments, allowing for the reliable separation of the effects of the tested independent variables. This approach reduced the possible source of unexplainable random variation that may arise from variable spray application conditions.

The leaves attached on the frame were sprayed from a distance of $1 \mathrm{~m}$ by the cross-flow orchard sprayer (Holder GmbH, Metzingen, Germany) with vertically oriented tangential fans producing horizontal air flow. The sprayer was driven past the frame at the travel velocity of $2 \mathrm{~m} \mathrm{~s}^{-1}$ (Figure 1). The spray liquid was atomized by six nozzles of two types: (i) conventional hollow-cone nozzles TR-80, producing fine spray; (ii) flat-fan air-inclusion nozzles ID-90, generating coarse spray. For each type, three nozzle sizes were used: 01, 02, and 03. The details on spray application parameters are given in Table 2.

The spray treatments were performed during favorable weather conditions. The relative air humidity was $70-75 \%$ and the temperature was $18-20^{\circ} \mathrm{C}$. The wind velocity was within the range of $1.0-2.0 \mathrm{~m} \mathrm{~s}^{-1}$, and it was blowing towards the spray collectors, perpendicularly to the sprayer's driven direction. 


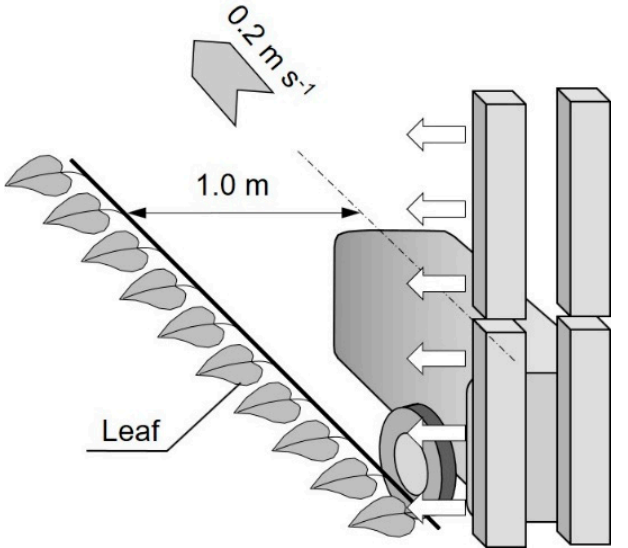

(A)

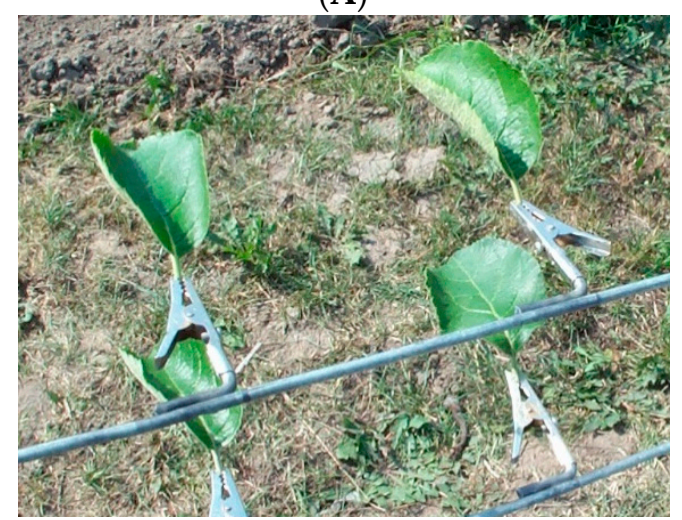

(C)

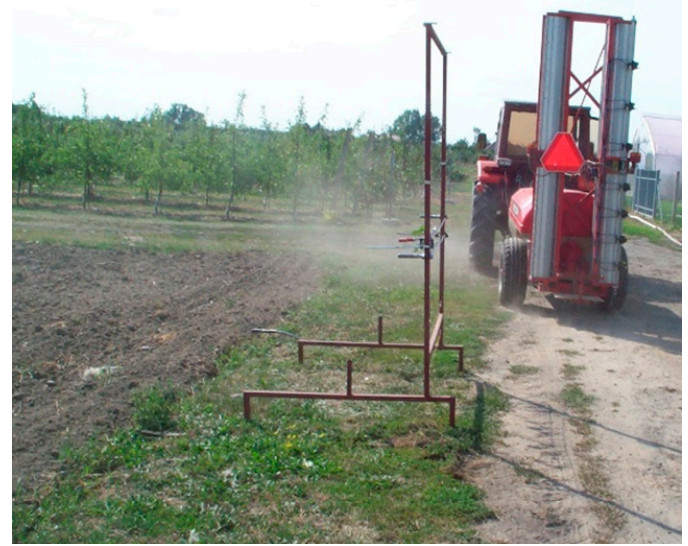

(B)

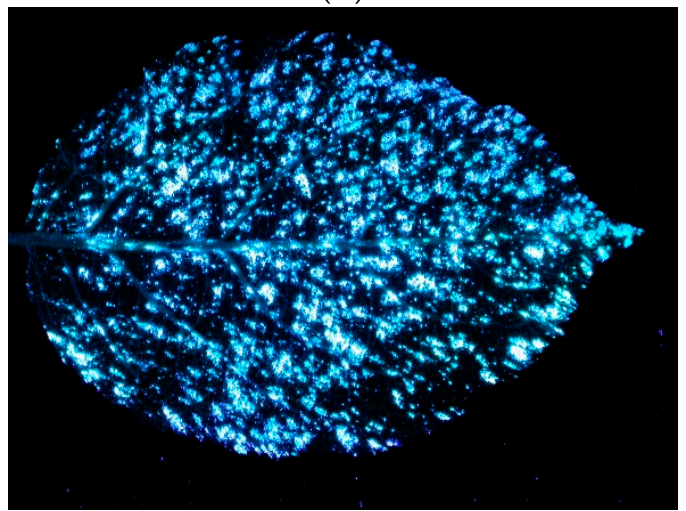

(D)

Figure 1. The layout of the experimental stand: (A) experimental scheme, (B) cross-flow sprayer (Holder GmbH, Metzingen, Germany), (C) apple leaves of Jonagold cv. as spray collectors, (D) spray coverage on apple leaf produced by flat fan air-inclusion nozzle (example).

Table 2. Parameters of adjuvants' application on apple leaves.

\begin{tabular}{|c|c|c|c|c|c|c|}
\hline Nozzle Type & $\begin{array}{l}\text { Nozzle Size * } \\
\text { [ISO] }\end{array}$ & $\begin{array}{l}\text { Pressure } \\
\text { [MPa] }\end{array}$ & $\begin{array}{c}\text { Droplet Size ** } \\
\text { [ISO] }\end{array}$ & $\begin{array}{l}\text { Travel } \\
\text { Speed } \\
{\left[\mathrm{m} \mathrm{s}^{-1}\right]}\end{array}$ & $\begin{array}{l}\text { Flow } \\
\text { Rate } \\
{\left[\mathrm{L} \min ^{-1}\right]}\end{array}$ & $\begin{array}{c}\text { Spray Volume } \\
\text { Rate } \\
{\left[\mathrm{L} \mathrm{ha}^{* *}\right]}\end{array}$ \\
\hline \multirow{3}{*}{$\begin{array}{l}\text { Hollow cone } \\
\text { TR-80 }\end{array}$} & 01 & 0.66 & Fine & \multirow{3}{*}{2.0} & 0.5 & 135 \\
\hline & 02 & 0.58 & Fine & & 1.04 & 260 \\
\hline & 03 & 0.55 & Medium & & 1.54 & 385 \\
\hline \multirow{3}{*}{$\begin{array}{l}\text { Flat fan } \\
\text { air-inclusion ID-90 }\end{array}$} & 01 & 0.66 & Very Coarse & \multirow{3}{*}{2.0} & 0.54 & 135 \\
\hline & 02 & 0.58 & Very Coarse & & 1.04 & 260 \\
\hline & 03 & 0.55 & Very Coarse & & 1.54 & 385 \\
\hline
\end{tabular}

* According to the standard ISO 10625:2018 [40]. ** For tap water, as given by the nozzle manufacturer (Lechler GmbH, Germany) based on the classification of droplet size spectra according to standard ISO 25358:2018 [41]. *** Assuming $4 \mathrm{~m}$ tree row spacing in orchard.

After the applications, when the spray was dry, the leaves were collected and stored in a cool, dark place. In the lab, each side of the leaves was photographed using a multifunctional microscope AZ100 (Nikon Corp., Tokyo, Japan) and digital camera COOLPIX 990 (Nikon Corp., Minato, Tokyo, Japan) under UV light $(375 \mathrm{~nm}$ ) in specially designed dark chamber. Then, three square spots of $1 \mathrm{~cm}^{2}$ each were sampled from each leaf image to determine spray coverage [\%] and droplet density (number of droplet stains per unit area) $\left[\mathrm{n} \mathrm{cm}^{-2}\right]$ with the NIS-Elements image analysis system (Nikon Corp., Minato, Tokyo, Japan).

The obtained data were analyzed using multi-way analysis of variance (ANOVA) to determine the effect of nozzle type and size, in addition to the kind of adjuvant and its 
concentration, on spray coverage and droplet density on the apple leaves. The analyses were carried out separately for each nozzle size $(01,02,03)$ in order to exclude the effect of the spray dose on the leaf coverage, which increases with the dose of the spray liquid. All statistical analyses were performed using STATISTICA 13. The treatment means were separated by Duncan's Multiple Range Test at the significance level $p<0.05$. The means are presented on bar graphs with confidence interval $95 \%$.

\section{Results and Discussion}

Many researchers have reported the effects of adjuvants and nozzles on droplet size and droplet velocity, spray coverage, and spray drift, in addition to the efficacy of plant protection products. However, they have not considered the influence of interaction between the adjuvants and the nozzles on spray distribution on the target, which is a crucial factor affecting the biological effect of chemical treatments. Most reported experiments were performed in labs, with the use of artificial collectors, and hence in conditions significantly different from those of a real spray application situation. The research presented here aimed to determine the effects of adjuvant concentration, nozzle type, and nozzle size, in addition to the interactions of these factors, on spray distribution on natural leaves fluttering in the air flow produced by a passing orchard sprayer.

The spray distribution was determined by measuring spray coverage expressed as a percentage of the target area covered by spray liquid, and droplet density as a count of drop stains per unit area of the target. Due to differences in the characteristics of the upper (U) and lower (L) surfaces of apple leaves, the two mentioned spray distribution indicators were analyzed and presented separately for each side of leaves. Data measured for each tested adjuvant was analyzed individually.

A question asked during the statistical analysis of the measured data was about the importance of the effects of the three tested factors on spray distribution on both sides of leaves. One means to determine the magnitude of effects of independent variables is to set proportions of the variances among the measured data that are attributable to these variables. In ANOVA, these proportions are estimated by ratios of the sum of the squares for each tested factor and the total sum of the squares. In the ANOVA summary table, they are presented as "percent of total" as a measure of the contribution of each factor and the interaction between the factors to the variation of the measured data, and thus reflect the magnitude of their effects [42].

\subsection{Experiment 1}

Due to different properties, individual adjuvants had different effects; however, for all of them. a common pattern was observed in the effects of nozzle type and adjuvant concentration on both the spray coverage and the droplet density. The statistical analysis shown in the ANOVA summary (Tables 3-5) indicates that the strongest factor affecting spray coverage on the upper side of the leaves was the nozzle type, which accounted for $30.86 \%$ of the total treatment variation for Agral, $26.62 \%$ for Silwet, and $23.19 \%$ for Greemax. This was followed by the adjuvant concentration, whose share in the total variation amounted to $14.72 \%, 7.61 \%$, and $12.71 \%$ respectively. The adjuvant concentration, in turn, clearly had the greatest effect on spray coverage on the lower side of leaves, accounting respectively for $33.24 \%, 19.99 \%$, and $45.62 \%$ of the total treatment variation. The contribution of nozzle type in this case was much lower, indicating the considerably weaker effect of this variable. In addition, the nozzle size, the variable which represents the spray volume rate, was the second most important factor affecting spray coverage on the lower leaf sides. For Silwet, this variable was almost as important as the adjuvant concentration (16.24\% versus $19.99 \%$, respectively, of the total treatment variation). The effect of the nozzle size on the spray coverage on the upper leaf surfaces was significant but minor compared to the effects of the nozzle type and adjuvant concentration. 
Table 3. The ANOVA summary table for data sets of spray coverage (A) and droplet density (B) on upper and lower surfaces of apple leaves obtained during the treatments with adjuvant Agral 90. The denotation ${ }^{N S}$ indicates not significant effects or interactions at $p<0.05$.

\begin{tabular}{|c|c|c|c|c|c|c|}
\hline \multirow{2}{*}{ Source of Variation } & \multirow{2}{*}{ df } & $\begin{array}{l}\text { Sum of } \\
\text { Squares }\end{array}$ & $\begin{array}{l}\text { Percent of } \\
\text { Total }\end{array}$ & \multirow{2}{*}{ df } & $\begin{array}{l}\text { Sum of } \\
\text { Squares }\end{array}$ & $\begin{array}{c}\text { Percent of } \\
\text { Total }\end{array}$ \\
\hline & & \multicolumn{2}{|c|}{ Upper Leaf Side } & & \multicolumn{2}{|c|}{ Lower Leaf Side } \\
\hline \multicolumn{7}{|c|}{ A. SPRAY COVERAGE } \\
\hline \multicolumn{7}{|l|}{ Main effects: } \\
\hline NT-Nozzle type & 1 & 3851.20 & 30.86 & 1 & 360.88 & 1.41 \\
\hline NS-Nozzle size & 2 & 871.14 & 6.98 & 2 & 736.97 & 2.88 \\
\hline AC-Adjuvant concentr. & 3 & 1837.98 & 14.72 & 3 & 8489.05 & 33.24 \\
\hline \multicolumn{7}{|l|}{ Interactions: } \\
\hline $\mathrm{NT} \times \mathrm{NS}$ & 2 & NS 43.72 & 0.35 & 2 & 780.56 & 3.05 \\
\hline $\mathrm{AC} \times \mathrm{NT}$ & 3 & 601.54 & 4.82 & 3 & 971.26 & 3.80 \\
\hline $\mathrm{AC} \times \mathrm{NS}$ & 6 & 516.89 & 4.14 & 6 & 868.32 & 3.40 \\
\hline $\mathrm{AC} \times \mathrm{NT} \times \mathrm{NS}$ & 6 & 309.48 & 2.48 & 6 & 810.15 & 3.17 \\
\hline ERROR & 216.0 & 4447.14 & 35.63 & 216.0 & $12,519.82$ & 49.02 \\
\hline TOTAL & & $12,479.13$ & & & $25,537.03$ & \\
\hline \multicolumn{7}{|c|}{ B. DROPLET DENSITY } \\
\hline \multicolumn{7}{|l|}{ Main effects: } \\
\hline NT-Nozzle type & 1 & $445,998.82$ & 15.42 & 1 & $4,343,543.20$ & 58.06 \\
\hline NS-Nozzle size & 2 & $71,176.23$ & 2.46 & 2 & $54,522.11$ & 0.72 \\
\hline AC-Adjuvant concentr. & 3 & $464,708.33$ & 16.07 & 3 & $384,813.67$ & 5.14 \\
\hline \multicolumn{7}{|l|}{ Interactions: } \\
\hline $\mathrm{NT} \times \mathrm{NS}$ & 2 & $49,746.43$ & 1.72 & 2 & $76,430.06$ & 1.02 \\
\hline $\mathrm{AC} \times \mathrm{NT}$ & 3 & NS $26,167.65$ & 0.91 & 3 & $574,164.05$ & 7.67 \\
\hline $\mathrm{AC} \times \mathrm{NS}$ & 6 & NS $39,594.46$ & 1.37 & 6 & $92,352.79$ & NS 1.23 \\
\hline $\mathrm{AC} \times \mathrm{NT} \times \mathrm{NS}$ & 6 & $234,962.20$ & 8.12 & 6 & $234,783.64$ & 3.13 \\
\hline ERROR & 216.0 & $1,559,786.60$ & 53.93 & 216.0 & $1,719,517.30$ & 22.98 \\
\hline TOTAL & & $2,892,140.73$ & & & $7,480,126.79$ & \\
\hline
\end{tabular}

Table 4. The ANOVA summary table for data sets of spray coverage (A) and droplet density (B) on upper and lower surfaces of apple leaves obtained during the treatments with adjuvant Silwet L-77. The denotation NS marks not significant effects or interactions at $p<0.05$.

\begin{tabular}{|c|c|c|c|c|c|c|}
\hline \multirow{2}{*}{ Source of Variation } & \multirow{2}{*}{ df } & $\begin{array}{l}\text { Sum of } \\
\text { Squares }\end{array}$ & $\begin{array}{l}\text { Percent of } \\
\text { Total }\end{array}$ & \multirow{2}{*}{ df } & $\begin{array}{l}\text { Sum of } \\
\text { Squares }\end{array}$ & $\begin{array}{c}\text { Percent of } \\
\text { Total }\end{array}$ \\
\hline & & \multicolumn{2}{|c|}{ Upper Leaf Side } & & \multicolumn{2}{|c|}{ Lower Leaf Side } \\
\hline \multicolumn{7}{|c|}{ A. SPRAY COVERAGE } \\
\hline \multicolumn{7}{|l|}{ Main effects: } \\
\hline NT-Nozzle type & 1 & 1283.82 & 26.619 & 1 & 531.93 & 4.07 \\
\hline NS-Nozzle size & 2 & 140.69 & 2.917 & 2 & 2124.88 & 16.24 \\
\hline AC-Adjuvant concentr. & 3 & 366.97 & 7.609 & 3 & 2614.96 & 19.99 \\
\hline \multicolumn{7}{|l|}{ Interactions: } \\
\hline $\mathrm{NT} \times \mathrm{NS}$ & 2 & 154.97 & 3.213 & 2 & NS 114.53 & 0.87 \\
\hline $\mathrm{AC} \times \mathrm{NT}$ & 3 & NS 49.67 & 1.030 & 3 & 298.61 & 2.28 \\
\hline $\mathrm{AC} \times \mathrm{NS}$ & 6 & NS 143.77 & 2.981 & 6 & 502.12 & 3.84 \\
\hline $\mathrm{AC} \times \mathrm{NT} \times \mathrm{NS}$ & 6 & NS 136.73 & 2.835 & 6 & NS 292.25 & 2.23 \\
\hline ERROR & 215.0 & 2546.27 & 52.795 & 216.0 & 6600.88 & 50.46 \\
\hline TOTAL & & 4822.91 & & & $13,080.17$ & \\
\hline
\end{tabular}


Table 4. Cont.

\begin{tabular}{|c|c|c|c|c|c|c|}
\hline \multirow{2}{*}{ Source of Variation } & \multirow{2}{*}{ df } & $\begin{array}{l}\text { Sum of } \\
\text { Squares }\end{array}$ & $\begin{array}{l}\text { Percent of } \\
\text { Total }\end{array}$ & \multirow{2}{*}{ df } & $\begin{array}{l}\text { Sum of } \\
\text { Squares }\end{array}$ & $\begin{array}{l}\text { Percent of } \\
\text { Total }\end{array}$ \\
\hline & & \multicolumn{2}{|c|}{ Upper Leaf Side } & & \multicolumn{2}{|c|}{ Lower Leaf Side } \\
\hline \multicolumn{7}{|c|}{ B. DROPLET DENSITY } \\
\hline \multicolumn{7}{|l|}{ Main effects: } \\
\hline NT-Nozzle type & 1 & $782,384.20$ & 25.79 & 1 & $7,451,145.60$ & 74.33 \\
\hline NS-Nozzle size & 2 & NS 4369.30 & 0.14 & 2 & NS $36,215.10$ & 0.36 \\
\hline AC-Adjuvant concentr. & 3 & $389,820.94$ & 12.85 & 3 & $222,056.98$ & 2.21 \\
\hline \multicolumn{7}{|l|}{ Interactions: } \\
\hline $\mathrm{NT} \times \mathrm{NS}$ & 2 & NS $30,508.93$ & 1.01 & 2 & $285,669.92$ & 2.85 \\
\hline $\mathrm{AC} \times \mathrm{NT}$ & 3 & $57,765.75$ & 1.90 & 3 & $279,002.66$ & 2.78 \\
\hline $\mathrm{AC} \times \mathrm{NS}$ & 6 & $147,958.17$ & 4.88 & 6 & $100,433.89$ & 1.00 \\
\hline $\mathrm{AC} \times \mathrm{NT} \times \mathrm{NS}$ & 6 & $246,278.87$ & 8.12 & 6 & $102,169.60$ & 1.02 \\
\hline ERROR & 216.0 & $1,374,471.30$ & 45.3 & 216.0 & $1,547,855.40$ & 15.44 \\
\hline TOTAL & & $3,033,557.46$ & & & $10,024,549.18$ & \\
\hline
\end{tabular}

Table 5. The ANOVA summary table for data sets of spray coverage (A) and droplet density (B) on upper and lower surfaces of apple leaves obtained during the treatments with adjuvant Greemax. The denotation NS marks not significant effects or interactions at $p<0.05$.

\begin{tabular}{|c|c|c|c|c|c|c|}
\hline \multirow{2}{*}{ Source of Variation } & \multirow{2}{*}{ df } & $\begin{array}{l}\text { Sum of } \\
\text { Squares }\end{array}$ & $\begin{array}{c}\text { Percent of } \\
\text { Total }\end{array}$ & \multirow[t]{2}{*}{ df } & $\begin{array}{l}\text { Sum of } \\
\text { Squares }\end{array}$ & $\begin{array}{c}\text { Percent of } \\
\text { Total }\end{array}$ \\
\hline & & \multicolumn{2}{|c|}{ Upper Leaf Side } & & \multicolumn{2}{|c|}{ Lower Leaf Side } \\
\hline \multicolumn{7}{|c|}{ A. SPRAY COVERAGE } \\
\hline \multicolumn{7}{|l|}{ Main effects: } \\
\hline NT-Nozzle type & 1 & 1970.26 & 23.19 & 1 & NS 71.83 & 0.27 \\
\hline NS-Nozzle size & 2 & 680.74 & 8.01 & 2 & 2009.24 & 7.65 \\
\hline AC-Adjuvant concentr. & 3 & 1080.01 & 12.71 & 3 & $11,977.81$ & 45.62 \\
\hline \multicolumn{7}{|l|}{ Interactions: } \\
\hline $\mathrm{NT} \times \mathrm{NS}$ & 2 & 280.74 & 3.30 & 2 & NS 107.31 & 0.41 \\
\hline $\mathrm{AC} \times \mathrm{NT}$ & 3 & 497.97 & 5.86 & 3 & NS 15.27 & 0.06 \\
\hline $\mathrm{AC} \times \mathrm{NS}$ & 6 & 302.92 & 3.56 & 6 & NS 308.34 & 1.17 \\
\hline $\mathrm{AC} \times \mathrm{NT} \times \mathrm{NS}$ & 6 & 552.51 & 6.50 & 6 & NS 175.06 & 0.67 \\
\hline ERROR & 216.0 & 3132.44 & 36.86 & 216.0 & $11,589.18$ & 44.14 \\
\hline TOTAL & & 8497.59 & & & $26,254.04$ & \\
\hline \multicolumn{7}{|c|}{ B. DROPLET DENSITY } \\
\hline \multicolumn{7}{|l|}{ Main effects: } \\
\hline NT-Nozzle type & 1 & $2,146,947.08$ & 27.91 & 1 & $4,184,895.59$ & 47.17 \\
\hline NS-Nozzle size & 2 & NS 8077.99 & 0.10 & 2 & NS 8008.97 & 0.09 \\
\hline AC-Adjuvant concentr. & 3 & $2,097,732.70$ & 27.27 & 3 & $658,528.15$ & 7.42 \\
\hline \multicolumn{7}{|l|}{ Interactions: } \\
\hline $\mathrm{NT} \times \mathrm{NS}$ & 2 & $117,657.27$ & 1.53 & 2 & $109,780.91$ & 1.24 \\
\hline $\mathrm{AC} \times \mathrm{NT}$ & 3 & $131,694.69$ & 1.71 & 3 & $837,687.23$ & 9.43 \\
\hline $\mathrm{AC} \times \mathrm{NS}$ & 6 & NS $99,227.03$ & 1.29 & 6 & NS $94,904.48$ & 1.07 \\
\hline $\mathrm{AC} \times \mathrm{NT} \times \mathrm{NS}$ & 6 & $286,827.52$ & 3.73 & 6 & $336,646.46$ & 3.79 \\
\hline ERROR & 216.0 & $2,803,427.12$ & 36.45 & 216.0 & $2,647,798.03$ & 29.82 \\
\hline TOTAL & & $769,159.42$ & & & $8,878,249.81$ & \\
\hline
\end{tabular}

Regarding the droplet density similarly strong effects of nozzle type and adjuvant concentration were found on the upper side of the leaves (Tables 3-5). They accounted respectively for $15.43 \%$ and $16.07 \%$ of total treatment variation in the case of Agral, $25.79 \%$ and $12.85 \%$ in the case of Silwet, and $27.91 \%$ and $27.27 \%$ in the case of Greemax. On the 
lower leaf sides, the droplet density was strongly affected by the nozzle type, which was clearly the strongest factor, responsible for as much as $58.2 \%, 74.33 \%$, and $47.17 \%$ of the total variation of the measured data for the respective adjuvants. The effects of nozzle size, i.e., the spray volume rate, on droplet density were not significant for the adjuvants Silwet and Greemax, whereas for Agral the effect was very weak, accounting for only $2.46 \%$ and $0.72 \%$ of total treatment variation on the upper and lower leaf surfaces, respectively. Because the droplet density was not, or hardly affected by, the nozzle size, it appears that the significant increase in spray coverage noted above, which was clearly not proportional to the increase in the applied spray volume rate, was mainly due to slightly coarser droplets, and thus greater droplet stains produced by the nozzles of the greater size, rather than a greater number of stains.

In the light of the above, the adjuvant concentration played an important role in modifying the spray coverage on the leaves, especially on their lower side where it was found to have a predominant effect. Clearly, the properties of the lower surface of the leaves better favor the spreading of droplets containing the adjuvant, and hence increasing the area covered by the spray liquid, than the properties of the upper surface. This is reflected in the results of spray coverage shown on Figures 2A, 3A and 4A, where higher values for all the tested adjuvants were recorded on the lower leaf surfaces than on the upper surfaces. This increase in coverage was not caused by an increase in droplet density, and in some cases occurred despite the reduction of this density due to droplet coalescing. Therefore, the adjuvant concentration had a minor effect on droplet density on the lower leaf surface, as proven by being a very weak source of variation among the measurement data collected for all the tested adjuvants (Tables 3-5). However, this variable showed an equally strong effect on droplet density on the upper leaf surface as the nozzle type on Agral and Greemax, and an effect that was half as strong as that of the nozzle type on Silwet.

In addition, it is worth noting that for the droplet density on the lower leaf surface, the effects of the interaction between nozzle type and adjuvant concentration for all the tested adjuvants were significant, accounting for $7.67 \%$ of the total treatment variation for Agral, 2.78\% for Silwet, and 9.43\% for Greemax (Tables 3-5). In these cases, the dependence of the adjuvant concentration effects on the nozzle type effects was particularly evident. The different nature of these relationships is shown in Figures 2B, 3B and 4B, namely: for the TR fine spray nozzles, the droplet density was generally decreasing with the increased adjuvant concentration, whereas for the ID coarse spray nozzles, it was either increasing or did not change significantly.

As mentioned above, for all treatments, spray coverage on the lower side of leaves was considerably greater than that on the upper sides (Figures 2A, 3A and $4 \mathrm{~A}$ ). In the case of Agral and Silwet, the difference was about two- or three-fold, whereas for Greemax it was up to about four-fold. This difference was greater for the ID nozzles than for the TR nozzles, mainly due to the very small coverage produced by the coarse spray nozzles on the upper leaf surfaces. This led to an unexpected situation, namely, there were no significant differences in coverage on the lower sides of leaves between the TR and the ID nozzles, regardless of the adjuvant concentration. In turn, on the upper surfaces, as expected, the coverage produced by the fine spray from the TR nozzles was, in most cases, significantly greater than that obtained by the coarse spray from the ID nozzles, for both pure water and tested aqueous adjuvant solutions. This finding may give rise to speculation about a possible connection between the target surface properties and different ways in which the impacting droplets of different size spread out on the surface. This is further discussed in the last paragraph of this section. Alternatively, it may be explained by the findings of [13], who observed the opposite situation as regards the percent area of spray coverage on the upper and lower sides of apple leaves (most probably due to different orientation of leaves in the tree canopy and those attached on the frame, compared to in this research); however, where this percentage was significantly greater (upper surface), there was no significant difference between the coverage produced by the standard (fine spray) and air-inclusion 
(coarse spray) nozzles. This may indicate that the high level of spray coverage minimizes or even nullifies the effect of droplet size, and hence that of the nozzle type. This may mean that this expected effect may only be significant in the case of poor coverage. Both speculated phenomena are likely to be feasible, which brings us to the conclusion that more in-depth research is necessary to clarify the dilemma.
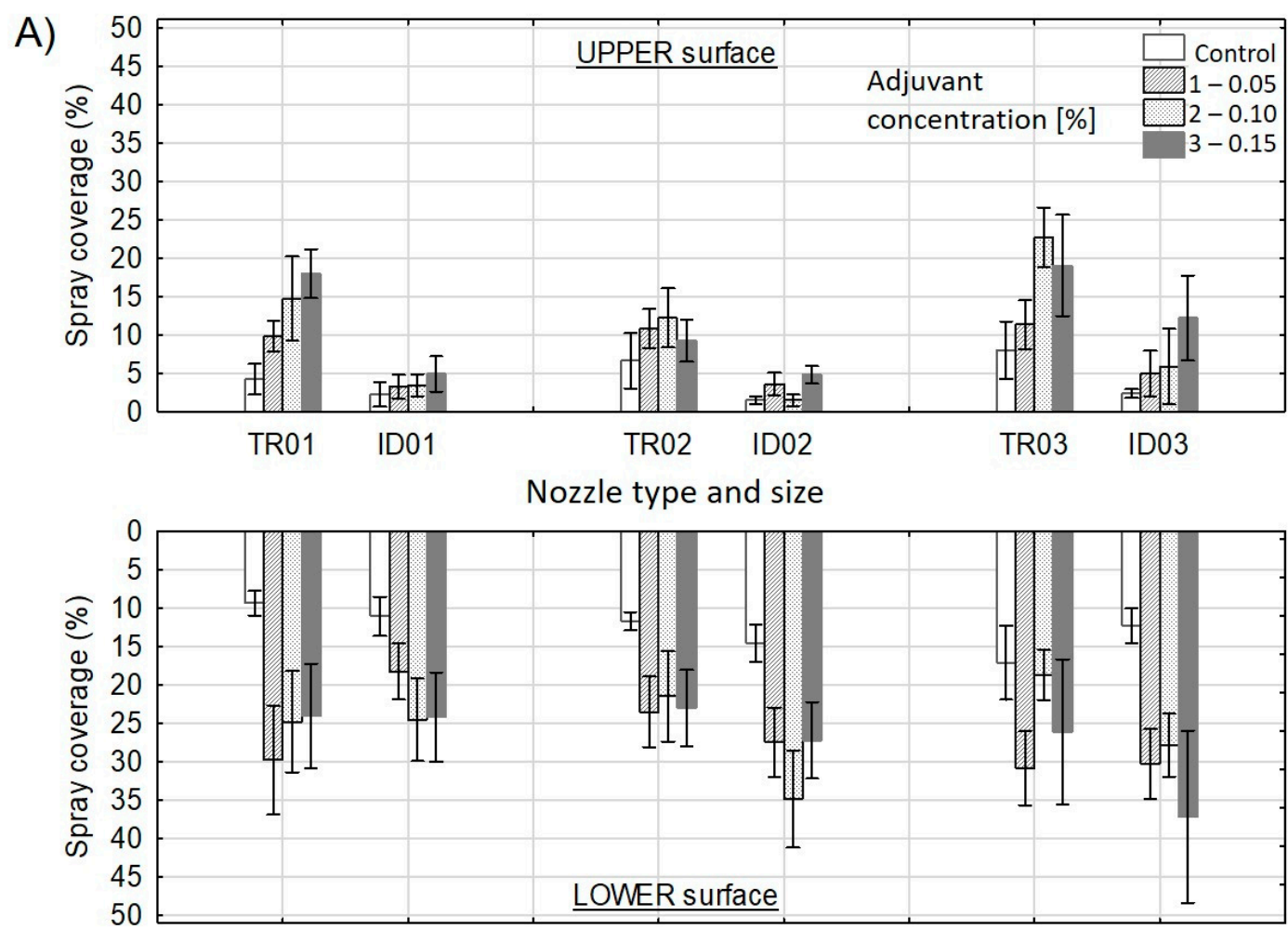

B)
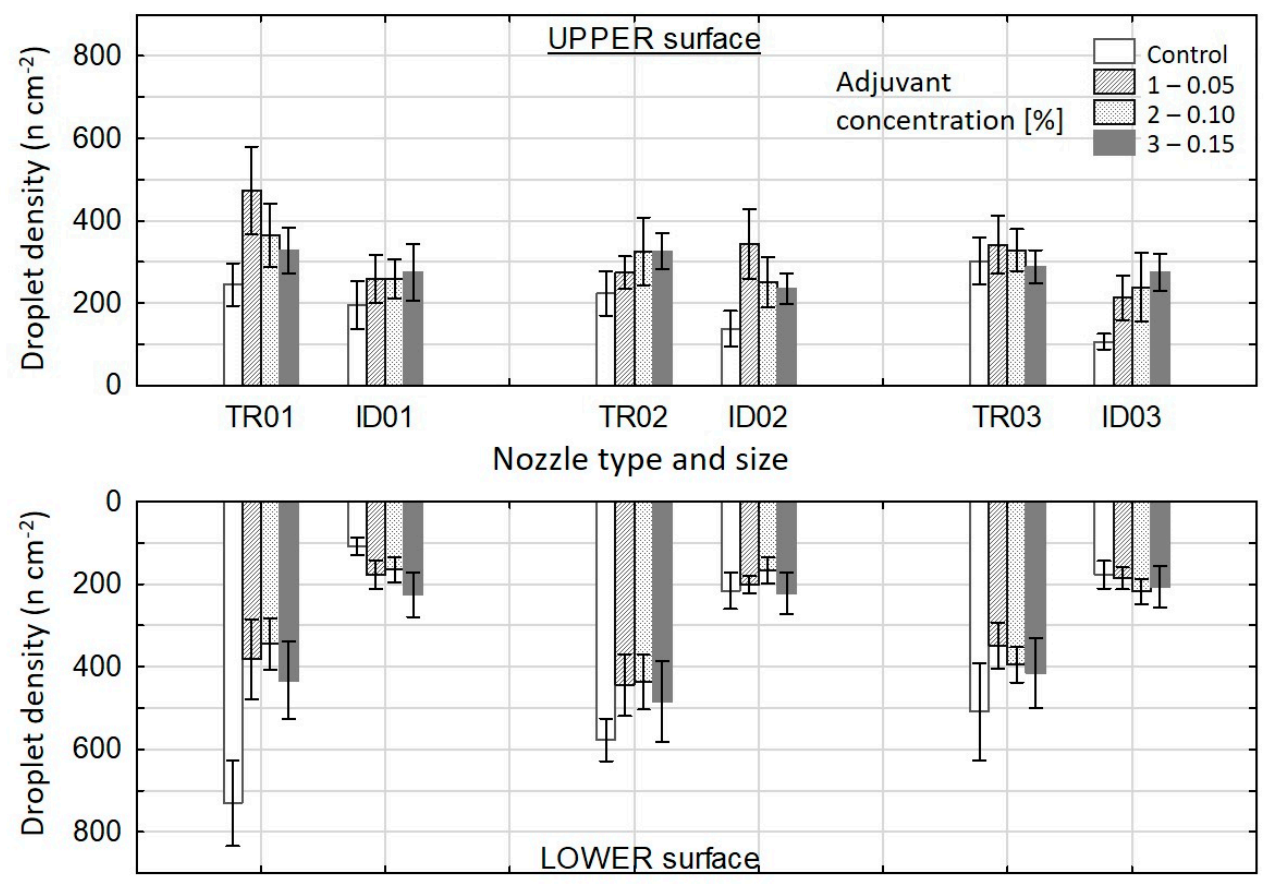

Figure 2. Effects of Agral 90 adjuvant concentration and nozzle type and size (TR-fine spray hollow cone nozzles; ID coarse spray flat fan air-inclusion nozzles); nozzle sizes 01, 02, 03 acc. to ISO 10625:2018 on: (A) spray coverage on the upper and lower leaf surface (\%) (mean); (B) droplet density on the upper and lower leaf surface $\left(\mathrm{n} \mathrm{cm}^{-2}\right)($ mean). 

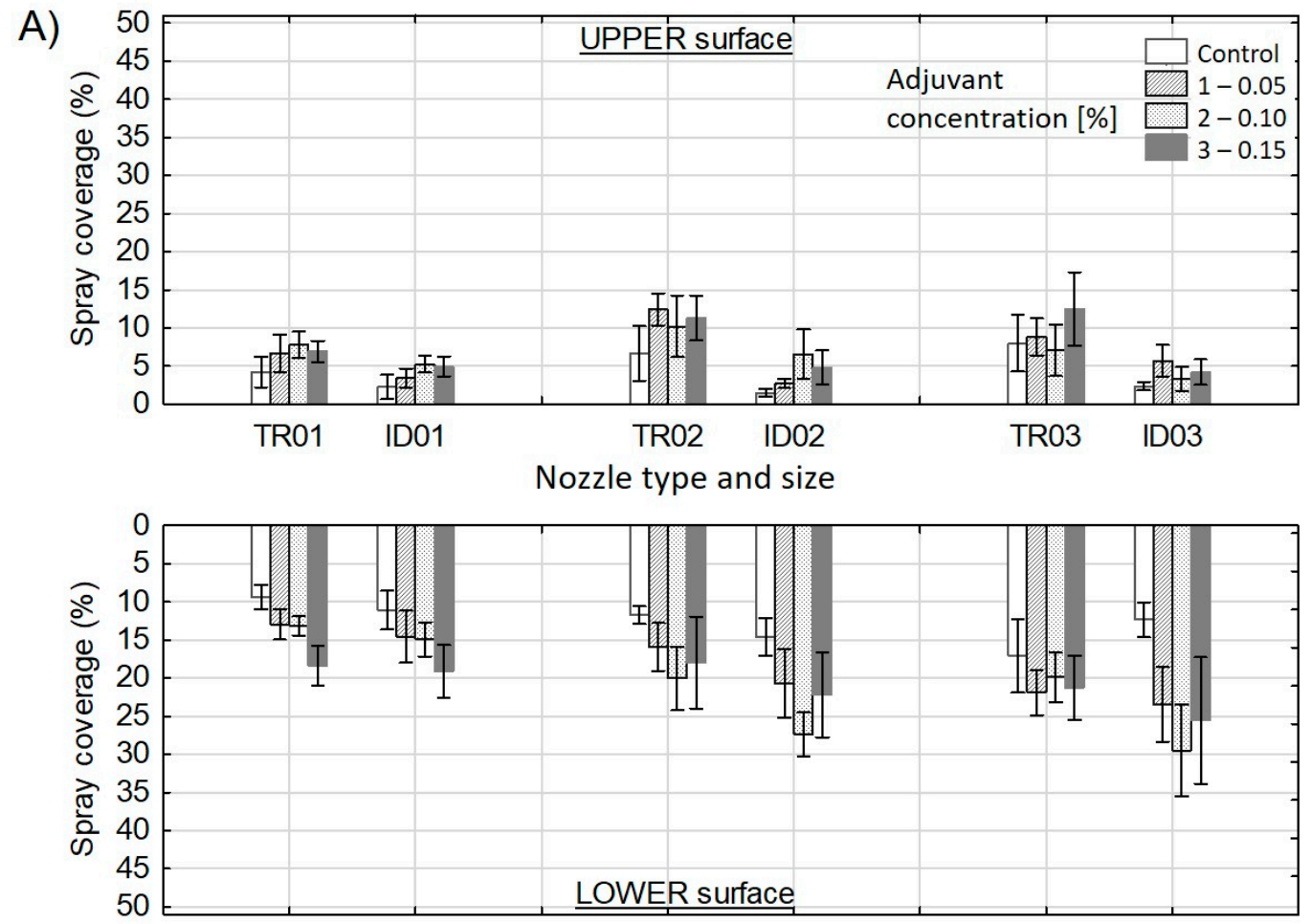

B)
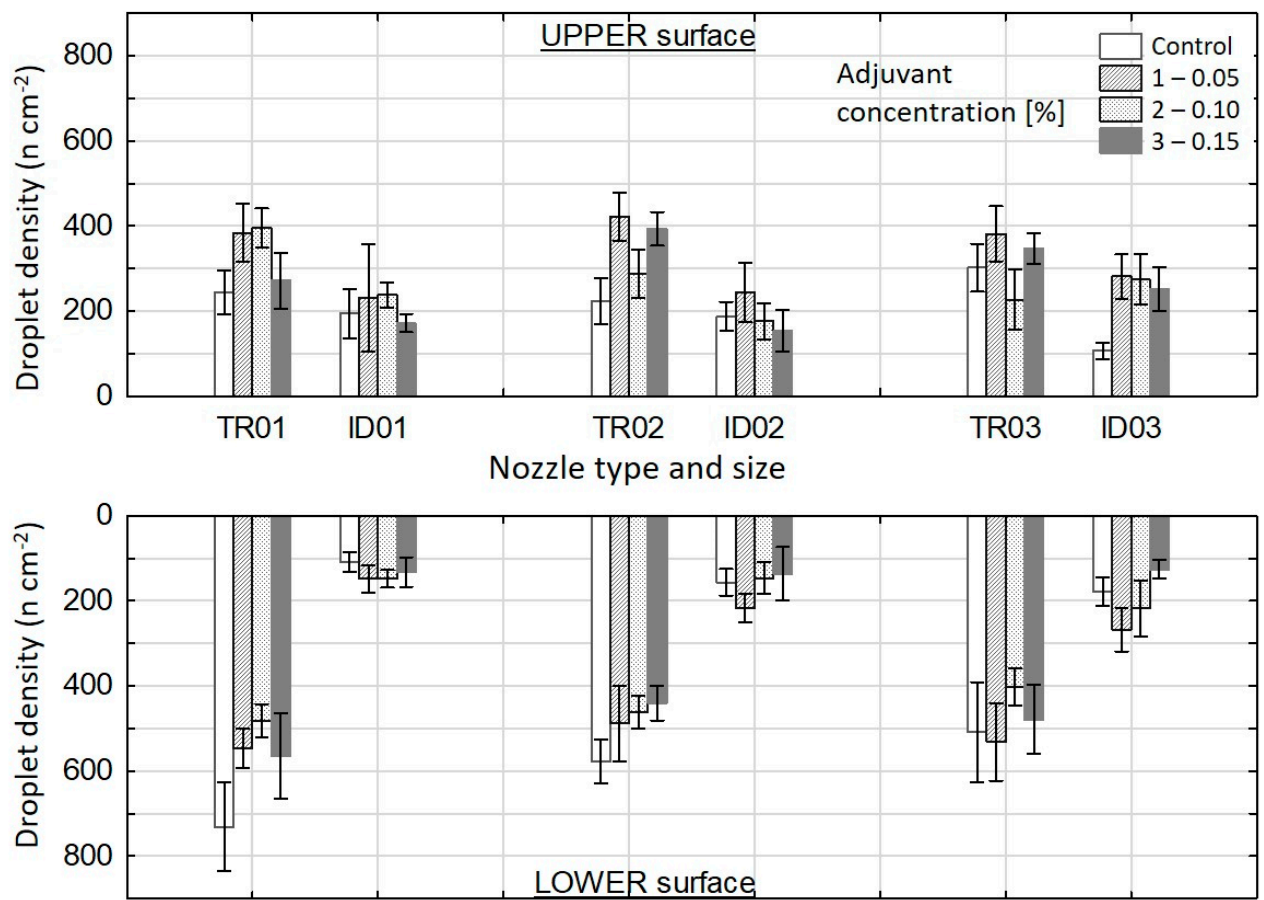

Figure 3. Effects of Silwet L-77 adjuvant concentration and nozzle type and size (TR-fine spray hollow cone nozzles; ID coarse spray flat fan air-inclusion nozzles); nozzle sizes 01, 02, 03 acc. to ISO 10625:2018 on: (A) spray coverage on the upper and lower leaf surface (\%) (mean); (B) droplet density on the upper and lower leaf surface $\left(\mathrm{n} \mathrm{cm}^{-2}\right)(\mathrm{mean})$. 
A)
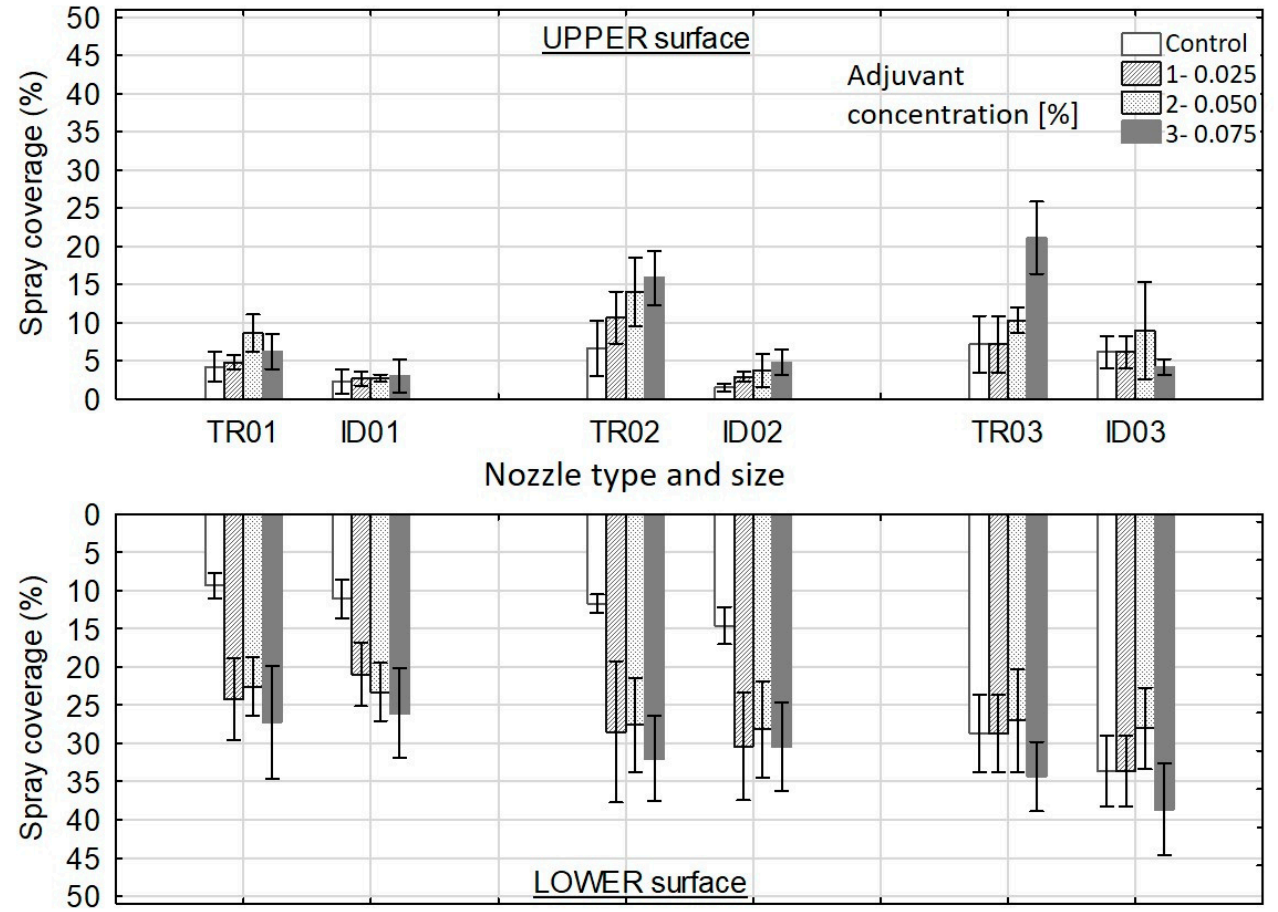

B)
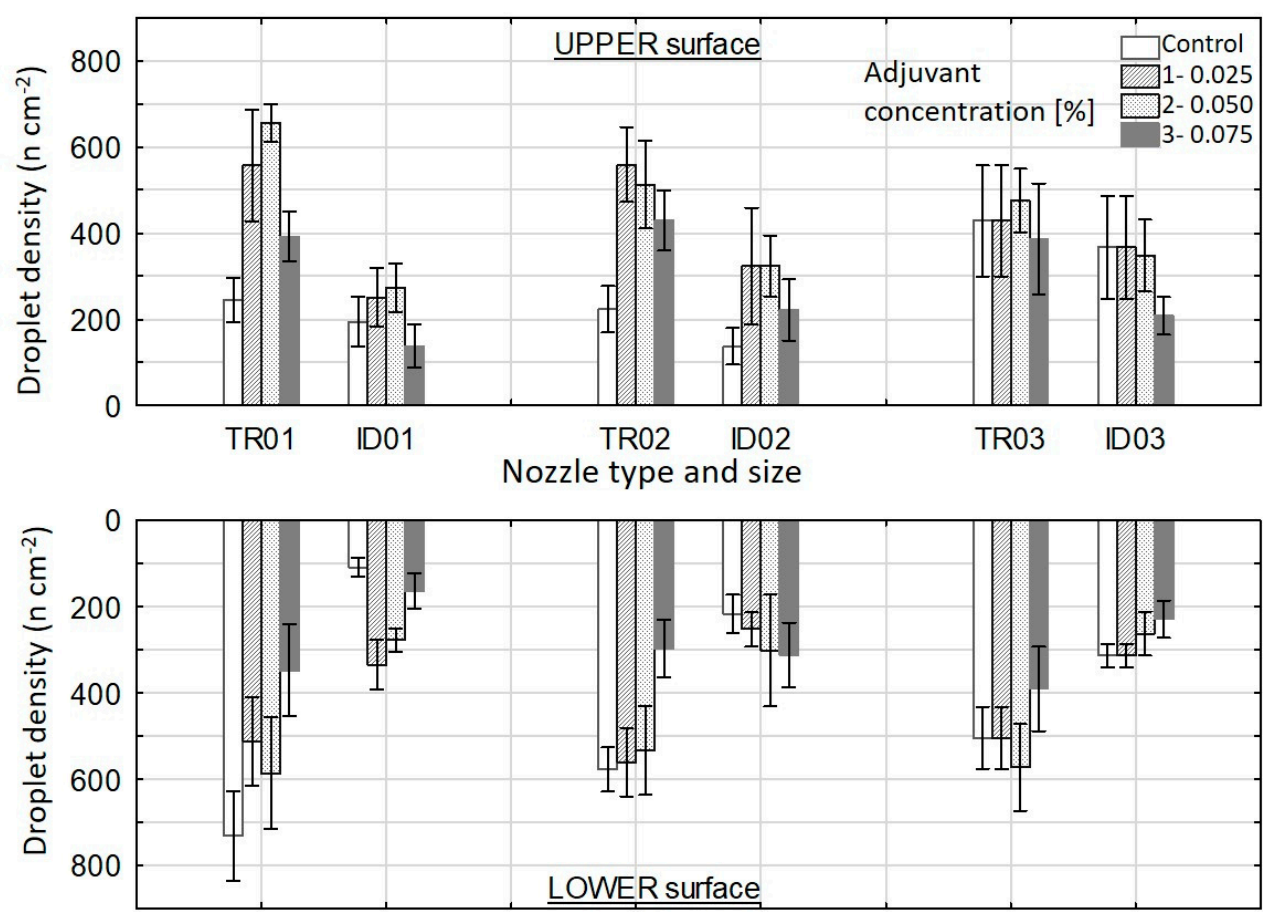

Figure 4. Effects of Greemax adjuvant concentration and nozzle type and size (TR-fine spray hollow cone nozzles; ID coarse spray flat fan air-inclusion nozzles); nozzle sizes 01, 02, 03 acc. to ISO 10625:2018 on: (A) spray coverage on the upper and lower leaf surface (\%) (mean); (B) droplet density on the upper and lower leaf surface $\left(\mathrm{n} \mathrm{cm}^{-2}\right)$ (mean).

Whether the adjuvants' modifying properties of the spray solution can compensate for the poor coverage produced by either type of nozzle may be explained by the results of this study. In most treatments, the adjuvants improved coverage even at the lowest concentrations (Figures 2A, 3A and 4A). Their further increase did not always significantly improve the coverage; however, on the upper surfaces, the highest concentrations of Agral and Greemax in most cases at least doubled or tripled the very low coverage (around 5\%) 
produced by pure water. A positive effect of adjuvant concentration was most evident on the lower leaf surfaces, again for Agral and Greemax. The nature of this effect was similar for TR and ID nozzles. On the upper surfaces, where coverage was relatively low and the effect of adjuvant concentration was moderate, the adjuvants failed to produce significantly better coverage by ID nozzles than that obtained by TR nozzles with no adjuvants. However, at the high concentrations, adjuvants at least equaled the coverage of the coarse spray with that of the fine spray of pure water. In this sense, the adjuvants well compensated for lower spray coverage obtained by the coarse spray compared to the fine spray. The most desired effect of better coverage obtained by ID nozzles and adjuvants, compared to that produced by TR nozzles and without adjuvants, was obvious on the lower surfaces of the leaves. In this case, adjuvants clearly showed their advantageous potential.

As mentioned above, the effect of adjuvant concentration on droplet density was relatively strong on the upper side of the leaves and minor on the lower side. The nature of the response of the droplet density to the adjuvant concentration was not clear, especially on the upper surfaces (Figures 2B, 3B and 4B). For most treatments, an increase in adjuvant concentration resulted in a reduction in droplet density due to the spreading and coalescing of the droplets on the leaves' surface. This was most evident on the lower side of leaves for the fine spray TR nozzles, whereas for the coarse spray ID nozzles, the response was mainly insignificant.

The observation that considerably higher coverage was obtained on the upper sides of leaves than on the lower sides requires an explanation and extended discussion. The way the leaves were attached and oriented on the frame, and their behavior in the air flow during spray application, made it possible to deposit a similar amount of spray on both sides. This was confirmed by the results of droplet density, which for all treatments showed very similar values for the upper and lower leaf surfaces (Figures 2B, 3B and 4B). Because both sides received a similar number of droplets, the different size of their stains must have caused such a large difference in coverage. Apparently, the droplets spread out differently on the upper and lower surfaces, and this may have been due to differences in the properties of the upper and lower epidermis of apple leaves. The upper epidermis is smooth and shiny due to a thick waxy and waterproof cuticle layer that protects the leaf from excess sunlight and prevents water loss. Therefore, it has a low surface energy, which prevents the liquid droplets from spreading widely, and the epidermis from being abundantly wetted. This leads to a high contact angle connecting the leaf-liquid interface, and hence a low percentage area of spray coverage. The apple leaves are hypostomatous, i.e., they have stomata only in the lower epidermis, which therefore is rougher than the upper epidermis. However, the roughness is extremely low, due to very high stomata density ranging from around 70 to 700 per $\mathrm{mm}^{2}$, depending on variety, timing, type of leaf, and growing conditions [43-45]. Moreover, on the lower leaf side there are other tiny epidermal outgrowths, such as trichomes (leaf hairs), the density of which may vary between 10 and 45 per $\mathrm{mm}^{2}$ [46-48]. Both stomata and trichomes on the lower leaf surface may interact with spray droplets and make them behave differently than on the smoother upper surface. This reasoning is supported by the findings of [46], who reported that spray retention was correlated significantly and positively with leaf hair density. Thus, it is highly likely that, upon spray deposition on the lower leaf epidermis, the densely distributed epidermal structures are in contact with droplets and disrupt the forces of liquid surface tension, causing the liquid to spread wider on the surface. In addition, the cuticle layer on the lower epidermis is considerably thinner than that on the upper epidermis, and is discontinuous due to the presence of stomata. This raises the surface energy of the lower epidermis, and thus reduces the leaf-liquid contact angle and lets the droplet create a wider stain (greater wetted area) than on the waxier, and hence more hydrophobic, upper epidermis. This is consistent with the results obtained by [49] on the leaves of Japanese Tree Lilac, which have a more hydrophobic lower epidermis, and by [50] on the hairy and waxy leaves of Geranium. In this research, this resulted in a greater spray coverage produced on the lower leaf sides than on the upper surfaces. 


\subsection{Experiment 2}

The effect of non-ionic adjuvant Silwet L-77 with the presence of the plant protection product Delan 700 WG (dithianon) on spray distribution on apple leaves was drastically different from that observed for the adjuvant alone. The most striking difference was the acquisition of much higher spray coverage on the upper leaf surfaces, in most cases exceeding $15 \%$, than on the lower surfaces, where for TR02 and TR03 nozzles, it hardly exceeded 5\% (Figure 5A). Another surprising observation on the lower leaf side was the effect of adjuvant concentration showing a negative coverage dose response relationship. In addition, unlike for the results of the lower surface coverage in Experiment 1, here the adjuvant concentration was the variable of minor importance, accounting for $8.68 \%$ of total treatment variation, compared to a contribution of $16.54 \%$ to the variation caused by the nozzle type. The opposite effect of adjuvant was observed on the upper surfaces, where the spray coverage clearly increased with the increase in adjuvant concentration (a positive dose response). Moreover, the adjuvant concentration and the nozzle type were the two most effective and equally important variables accounting for, respectively, $16.73 \%$ and $15.52 \%$ of the total treatment variation.

The fungicide Delan 700 WG used in this experiment is a water-soluble granulatecreating aqueous suspension, for which kaolinite is used as a carrier of an active substance. The intrinsic mineral anionic adjuvant of this product is ammonium sulphate $\left(\mathrm{NH}_{4}\right)_{2} \mathrm{SO}_{4}$, which has no particular wetting properties of non-ionic surfactants, such as Silwet. The primary function of this adjuvant is mitigation of water hardness by complexing metal cations (mainly $\mathrm{Ca}^{2+}, \mathrm{Mg}^{2+}, \mathrm{Fe}^{3+}, \mathrm{Mn}^{+}$, and $\mathrm{Na}^{+}$) to prevent formation of precipitate, and hence avoid deactivation of the active substance. However, anionic adjuvants are lipophilic compounds, dissolving lipids such as cuticles, to increase the mobility of the agrochemicals across the cuticular membrane [51]. They act as plasticizers that soften the crystalline waxes in the cuticle, and thus increase cuticular penetration, and possibly widen the wetting area of the spray droplets on the waxy leaf surface. In the presented experiment, a synergic interaction between the intrinsic lipophilic adjuvant of Delan fungicide and the surface active Silwet adjuvant may have occurred, making the spray droplets spread very widely on the waxy upper surfaces of apple leaves, and thus resulting in very high spray coverage, and a clearly positive coverage dose response relationship. This was observed in each of the six tested treatments, i.e., for both nozzle types and three nozzle sizes. It does not, however, explain the very poor coverage observed on the lower leaf surfaces. In addition, the role of kaolinite as a structural component of the fungicide formulation in the spray distribution on the leaves is unknown. This suggests further research is needed on the effects of the interaction between the formulations of plant protection products and adjuvants added to spray liquid on the spray distribution on different targets.

The surprising and unclear picture of spray coverage on apple leaves was not reflected in the results of droplet density. Here, the nozzle type was a dominant factor, accounting for nearly $40 \%$ of the total treatment variation, both for the upper and lower sides of leaves, whereas the contributions of adjuvant concentration were $10.58 \%$ and $9.50 \%$, respectively (Table 6B). On the upper leaf surface, the droplet density for TR nozzles was, on average, about two-fold higher than for ID nozzles, and on the lower surface the difference was nearly three-fold (Figure 5B). In most cases, on both sides of the leaves, the addition of Silwet adjuvant at the lowest concentration increased the droplet density, but a further increase in the adjuvant concentration caused its gradual drop, even below the level obtained for pure water. This trend, however, was not consistent over all the treatments, and thus the interaction between the adjuvant concentration and the nozzle type was significant. This was similar to the results obtained for the adjuvant Silwet alone, i.e., with no presence of the fungicide (Figure 3B); however, both the downward trend of the dose response and the interaction with the nozzle type were more pronounced than in Experiment 1. This may have been an effect of an antagonistic activity of the intrinsic adjuvant of Delan fungicide against the surface tension activity of Silwet, which interfered with the liquid atomization process and resulted in the production of fewer droplets of greater size. Similar to the results obtained for coverage, the 
droplet density on the upper leaf surfaces was generally two-fold greater than that on the lower sides.
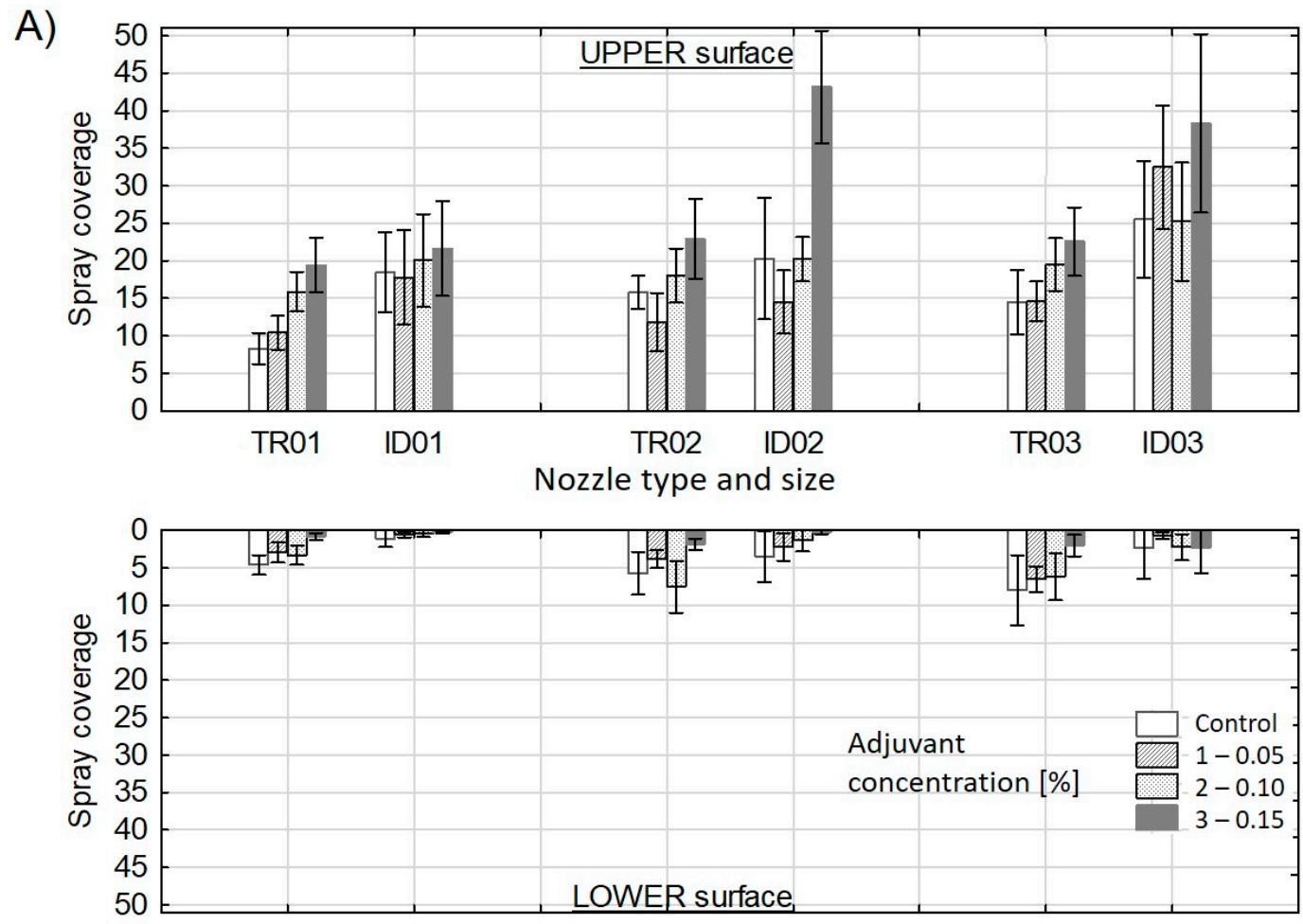

B)
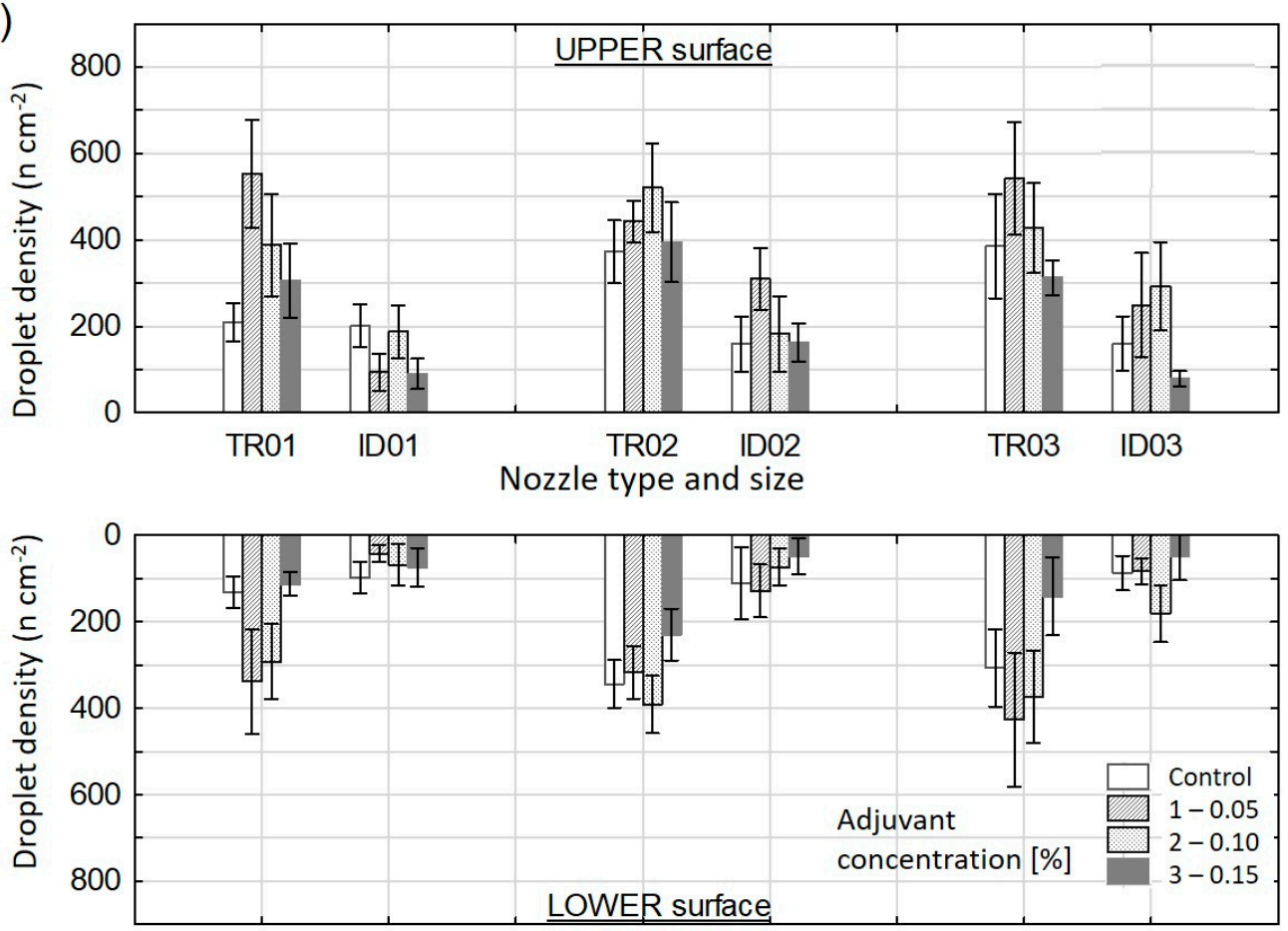

Figure 5. Effects of Silwet L-77 adjuvant concentration in spray liquid based on fungicide (dithianon-Delan 700 WG) and nozzle type and size (TR-fine spray hollow cone nozzles; ID coarse spray flat fan air-inclusion nozzles); nozzle sizes 01, 02, 03 acc. to ISO 10625:2018 on: (A) spray coverage on the upper and lower leaf surface (\%) (mean); (B) droplet density on the upper and lower leaf surface $\left(\mathrm{n} \mathrm{cm}^{-2}\right)$ (mean). 
Table 6. The ANOVA summary table for data sets of spray coverage (A) and droplet density (B) on upper and lower surfaces of apple leaves obtained during the treatments with adjuvant Silwet L-77 + Delan 700 WG. The denotation NS marks not significant effects or interactions at $p<0.05$.

\begin{tabular}{|c|c|c|c|c|c|c|}
\hline \multirow{2}{*}{ Source of Variation } & \multirow{2}{*}{ df } & $\begin{array}{l}\text { Sum of } \\
\text { Squares }\end{array}$ & $\begin{array}{c}\text { Percent of } \\
\text { Total }\end{array}$ & \multirow{2}{*}{ df } & $\begin{array}{l}\text { Sum of } \\
\text { Squares }\end{array}$ & $\begin{array}{c}\text { Percent of } \\
\text { Total }\end{array}$ \\
\hline & & \multicolumn{2}{|c|}{ Upper Leaf Side } & & \multicolumn{2}{|c|}{ Lower Leaf Side } \\
\hline \multicolumn{7}{|c|}{ A. SPRAY COVERAGE } \\
\hline \multicolumn{7}{|l|}{ Main effects: } \\
\hline NT-Nozzle type & 1 & 4491.94 & 15.52 & 1 & 548.43 & 16.54 \\
\hline NS-Nozzle size & 2 & 2321.61 & 8.02 & 2 & 180.06 & 5.43 \\
\hline AC-Adjuvant concentr. & 3 & 4840.24 & 16.73 & 3 & 287.71 & 8.68 \\
\hline \multicolumn{7}{|l|}{ Interactions: } \\
\hline $\mathrm{NT} \times \mathrm{NS}$ & 2 & 482.95 & 1.67 & 2 & NS 21.06 & 0.63 \\
\hline $\mathrm{AC} \times \mathrm{NT}$ & 3 & 578.89 & 2.00 & 3 & 122.35 & 3.69 \\
\hline $\mathrm{AC} \times \mathrm{NS}$ & 6 & 1414.60 & 4.89 & 6 & NS 23.62 & 0.71 \\
\hline $\mathrm{AC} \times \mathrm{NT} \times \mathrm{NS}$ & 6 & 1157.77 & 4.00 & 6 & NS 96.66 & 2.92 \\
\hline ERROR & 216.0 & $13,646.93$ & 47.16 & 216.0 & 2035.21 & 61.39 \\
\hline TOTAL & & $28,934.94$ & & & 3315.11 & \\
\hline \multicolumn{7}{|c|}{ B. DROPLET DENSITY } \\
\hline \multicolumn{7}{|l|}{ Main effects: } \\
\hline NT-Nozzle type & 1 & $3,001,383.00$ & 39.011 & 1 & $2,321,846.82$ & 39.67 \\
\hline NS-Nozzle size & 2 & $190,066.57$ & 2.470 & 2 & $198,662.72$ & 3.39 \\
\hline AC-Adjuvant concentr. & 3 & $813,718.25$ & 10.577 & 3 & $555,928.22$ & 9.50 \\
\hline \multicolumn{7}{|l|}{ Interactions: } \\
\hline $\mathrm{NT} \times \mathrm{NS}$ & 2 & NS 888.36 & 0.012 & 2 & $74,393.41$ & 1.27 \\
\hline $\mathrm{AC} \times \mathrm{NT}$ & 3 & $159,083.01$ & 2.068 & 3 & $275,456.15$ & 4.71 \\
\hline $\mathrm{AC} \times \mathrm{NS}$ & 6 & NS 75357.99 & 0.979 & 6 & NS $98,849.81$ & 1.69 \\
\hline $\mathrm{AC} \times \mathrm{NT} \times \mathrm{NS}$ & 6 & $520,645.07$ & 6.767 & 6 & $207,168.92$ & 3.54 \\
\hline ERROR & 216.0 & $2,932,497.90$ & 38.116 & 216.0 & $2,120,186.60$ & 36.23 \\
\hline TOTAL & & $7,693,640.16$ & & & $5,852,492.65$ & \\
\hline
\end{tabular}

Both nozzle type and adjuvant concentration were important factors influencing the spray coverage on apple leaves. Only on the upper leaf surface, where the nozzle type was the most effective variable, the coverage obtained by the fine spray TR nozzles was, with all tested adjuvants, greater than that obtained by coarse spray ID nozzles. On the lower leaf surface, where the adjuvant concentration was the dominant variable, the coverage obtained with the adjuvant Silwet L-77 for the ID nozzles was greater than that for the TR nozzles, whereas with adjuvants Agral 90 and Greemax no differences in coverage between the nozzle types were observed.

In general, a greater coverage was obtained on the lower leaf surface than on the upper, even though the droplet density was similar on both surfaces. This may have been due to different epidermal properties of the upper and lower surfaces of apple leaves. The epidermal structures of the lower surface, such as stomata and trichomes, can make droplets spread wider, resulting in higher coverage than on the smoother and waxier surface of the upper, which is less prone to wetting.

The increase in adjuvant concentration caused a positive coverage dose response relationship. However, the maximum coverage was not always obtained at the highest adjuvant concentration, especially for adjuvants Silwet L-77 and Agral 90 on the lower leaf surface.

Overall, the coverage produced by the tested adjuvants at the high concentrations with the coarse spray ID nozzles generally equaled that produced by the fine spray nozzles TR applying pure water. Thus, as expected, the adjuvants showed their potential to 
compensate for the lower spray coverage usually obtained by the coarse spray compared to the fine spray.

\section{Conclusions}

Droplet density on both leaf surfaces with all tested adjuvants was considerably higher for fine spray TR nozzles than coarse spray ID nozzles. The nozzle type clearly made the greatest contribution to the variation of the droplet density on the lower leaf surface, whereas on the upper, both the nozzle type and the adjuvant concentration were equally important variables. The influence of the adjuvant concentration on droplet density on the upper leaf surface was diverse in the case of each tested adjuvant. In most treatments, the droplet density significantly increased at the lowest adjuvant concentration, and when it was further increased, the droplet density decreased or remained unchanged. On the lower leaf surface, the increase in adjuvant concentration usually caused a negative droplet density dose response relationship.

The plant protection product Delan 700 WG (dithianon) applied with the adjuvant Silwet L-77 produced opposing results for both the coverage and the droplet density on the upper and lower leaf sides compared to the results obtained for Silwet alone. In this case, both spray distribution indicators were greater on the upper surface of leaves. In this experiment, the nozzle type played the major role as a dominant factor affecting spray distribution quality, whereas the adjuvant concentration was of secondary importance. This reduction in the adjuvant effect may have been caused by the antagonistic activity of the intrinsic adjuvant of Delan fungicide (ammonium sulphate) against the surface tension activity of the non-ionic adjuvant Silwet. Alternatively, it may have been due to the interference of kaolinite, which is a structural component of the fungicide formulation, in the atomization process and the spray distribution on the leaves. These effects were also reflected in the negative response of coverage and droplet density on the lower leaf surfaces to the increase in adjuvant concentration.

Author Contributions: Conceptualization, methodology, investigation, writing-original draft preparation, R.H. and G.D.; investigation R.H., G.D., W.Ś. and A.G.; formal analysis, writing-review \& editing, data curation, W.Ś. and P.K.; resources, visualization, A.G.; validation, P.K.; supervision, R.H. All authors have read and agreed to the published version of the manuscript.

Funding: The described research and article preparation were undertaken within the statutory research task of the National Institute of Horticultural Research, Skierniewice, Poland, subordinated to the Ministry of Agriculture and Rural Development, and in the research area financed by the Ministry of Science and Higher Education of the Republic of Poland.

Conflicts of Interest: The authors declare no conflict of interest.

\section{References}

1. Al Heidary, M.; Douzals, J.P.; Sinfort, C.; Vallet, A. Influence of spray characteristics on potential spray drift of field crop sprayers: A literature review. Crop Prot. 2014, 63, 120-130. [CrossRef]

2. Holownicki, R.; Doruchowski, G.; Godyn, A.; Swiechowski, W. Effects of air jet adjustment on spray losses in orchard. Asp. Appl. Biol. 2000, 57, 293-300.

3. Hilz, E.; Vermeer, A.W.P. Spray drift review: The extent to which a formulation can contribute to spray drift reduction. Crop Prot. 2013, 44, 75-83. [CrossRef]

4. Jensen, P.K. Influence of air-assistance to flat fan and air-induction nozzles and the use of nozzle sledge on the activity of haloxyfop against ryegrass. Asp. Appl. Biol. 2002, 66, 73-78.

5. Wolf, T.M. Low-drift nozzle efficacy with respect to herbicide mode of action. Asp. Appl. Biol. 2000, 57, $29-34$.

6. Frießleben, R. Influence of coarse droplet applications via injector nozzles on biological efficacy in apple production. In Proceedings of the VII Workshop on Spray Application in Fruit Growing, Cuneo, Italy, 25-27 July 2003; pp. $109-115$.

7. Lešnik, M.; Pintar, C.; Lobnik, A.; Kolar, M. Comparison of the effectiveness of standard and drift-reducing nozzles for control of some pests of apple. Crop Prot. 2005, 24, 93-100. [CrossRef]

8. Heinkel, R.; Fried, A.; Lange, E. The effect of air injector nozzles on crop penetration and biological performance of fruit sprayers. Asp. Appl. Biol. 2000, 57, 301-307.

9. Jaeken, P.; de Maeyer, L.; Broers, N.; Creemers, P. Nozzle choice and its effect on spray deposit and distribution, uptake, drift and biological efficacy in standard apple orchards (Malus sylvestris, cv Jonagold). Pflanzensch. Nachr. Bayer. 2003, 56, 326-353. 
10. Knewitz, H.; Weisser, P.; Koch, H. Drift-reducing spray application in orchards and biological efficacy of pesticides. Asp. Appl. Biol. 2002, 66, 231-236.

11. Fornasiero, D.; Mori, N.; Tirello, P.; Pozzebon, A.; Duso, C.; Tescari, E.; Bradascio, R.; Otto, S. Effect of spray drift reduction techniques on pests and predatory mites in orchards and vineyards. Crop Prot. 2017, 98, 283-292. [CrossRef]

12. Doruchowski, G.; Świechowski, W.; Masny, S.; Maciesiak, A.; Tartanus, M.; Bryk, H.; Hołownicki, R. Low-drift nozzles vs. standard nozzles for pesticide application in the biological efficacy trials of pesticides in apple pest and disease control. Sci. Total Environ. 2017, 575, 1239-1246. [CrossRef]

13. Derksen, R.C.; Zhu, H.; Fox, R.D.; Brazee, R.D.; Krause, C.R. Coverage and Drift Produced by Air Induction and Conventional Hydraulic Nozzles Used for Orchard Applications. Trans. ASABE 2007, 50, 1493-1501. [CrossRef]

14. Holownicki, R.; Doruchowski, G.; Świechowski, W.; Godyn, A. VarioWindSelect system for automatic adjustment of nozzle type to the wind velocity in order to decrease spray drift in orchard. In Proceedings of the 7th International ATW-Symposium on Technology Application in Horti- and Viticulture, Stuttgart, Germany, 10-11 May 2004; pp. 36-42.

15. Doruchowski, G.; Swiechowski, W.; Holownicki, R.; Godyń, A. Environmentally-Dependent Application System for safer spray application in fruit growing. J. Hortic. Sci. Biotechnol. 2009, 84, 107-112. [CrossRef]

16. Spanoghe, P.; Steurbaut, W.; van der Meeren, P. The effect of adjuvants on spray performance by use of nozzles with different orifices. Asp. Appl. Biol. 2002, 66, 251-256.

17. Hoffmann, W.C.; Hewitt, A.J.; Barber, J.A.S.; Kirk, I.W.; Brown, J.R. Field Swath and Drift Analyses Techniques; ASAE Paper, No. AA032007; ASAE: St. Joseph, MI, USA, 2003.

18. Celen, I.H. The effect of spray mix adjuvants on spray drift. Bulg. J. Agric. Sci. 2010, 16, 105-110.

19. Carlsen, S.C.K.; Spliid, N.H.; Svensmark, B. Drift of 10 herbicides after tractor spray application. 2. Primary drift (droplet drift). Chemosphere 2006, 64, 778-786. [CrossRef] [PubMed]

20. Holloway, P.J.; Butler Ellis, M.C.; Webb, D.A.; Western, N.M.; Tuck, C.R.; Hayes, A.L.; Miller, P.C.H. Effects of some agricultural tank-mix adjuvants on the deposition efficiency of aqueous sprays on foliage. Crop Prot. 2000, 19, 27-37. [CrossRef]

21. Stainier, C.; Destain, M.F.; Schiffers, B.; Lebeau, F. Droplet size spectra and drift effect of two phenmedipham formulations and four adjuvants mixtures. Crop Prot. 2006, 25, 1238-1243. [CrossRef]

22. Butler Ellis, M.C.; Tuck, C.R.; Miller, P.C.H. The effect of some adjuvants on sprays produced by agricultural flat fan nozzles. Crop Prot. 1997, 16, 41-50. [CrossRef]

23. Sanderson, R.; Hewitt, A.J.; Huddleston, E.W.; Ross, J.B. Relative drift potential and droplet size spectra of aerially applied Propanil formulations. Crop Prot. 1997, 16, 717-721. [CrossRef]

24. Xu, L.; Zhu, H.; Ozkan, E.; Bagley, W.E.; Krause, C.R. Droplet evaporation and spread on waxy and hairy leaves associated with type and concentration of adjuvants. Pest Manag. Sci. 2011, 67, 842-851. [CrossRef]

25. Butler Ellis, M.C.; Bradley, A. Influence of formulation on spray drift. Asp. Appl. Biol. 2002, 66, $251-258$.

26. Butler Ellis, M.C.; Tuck, C.R. The variation in characteristics of air-included sprays with adjuvants. Asp. Appl. Biol. 2000, 57, 155-162.

27. De Schampheleire, M.; Nuyttens, D.; Baetens, K.; Cornelis, W.; Gabriels, D.; Spanoghe, P. Effects on pesticide spray drift of the physicochemical properties of the spray liquid. Prec. Agric. 2009, 10, 409-420. [CrossRef]

28. Spanoghe, P.; de Schampheleire, M.; van der Meeren, P.; Steurbaut, W. Review Influence of agricultural adjuvants on droplet spectra. Pest Manag. Sci. 2007, 63, 4-16. [CrossRef] [PubMed]

29. Zhu, H.; Zondag, R.H.; Derksen, R.C.; Reding, M.; Krause, C.R. Influence of spray volume on spray deposition and coverage within nursery trees. J. Environ. Hortic. 2008, 26, 51-57. [CrossRef]

30. Forester, W.A.; Gaskin, R.E.; Strand, T.M.; Manktelow, D.W.L.; Leeuwen, R.M. Effect of target wettability on spray droplet adhesion, retention, spreading and coverage: Artificial collectors versus plant surfaces. N. Z. Plant Prot. 2014, 67, $284-291$. [CrossRef]

31. Powell, E.S.; Orson, J.H.; Miller, P.C.H.; Kudsk, P.; Mathiassen, S. Defining the size of target for air induction nozzles. Asp. Appl. Biol. 2002, 66, 65-72.

32. Arnold, A.C. A comparative study of droplet sizing equipment for agricultural fan-spray atomizers. Aerosol Sci. Technol. 1990, 12, 431-445. [CrossRef]

33. Herbst, A. Droplet sizing on agricultural sprays: A comparison of measuring systems using a standard droplet size classification scheme. In Proceedings of the 17th Annual Conference on Liquid Atomization and Spray Systems (ILASSEurope), Zürich, Switzerland, 2-6 January 2001; pp. 371-402.

34. Gimenes, M.J.; Zhu, H.; Raetano, C.G.; Oliveira, R.B. Dispersion and evaporation of droplets amended with adjuvants on soybeans. Crop Prot. 2013, 44, 84-90. [CrossRef]

35. Lin, H.; Zhou, H.; Xu, L.; Zhu, H. Effect of surfactant concentration on the spreading properties of pesticides droplets on Eucalyptus leaves. Biosyst. Eng. 2016, 143, 42-49. [CrossRef]

36. Yu, Y.; Zhu, H.; Ozkan, H.E.; Derksen, R.C.; Krause, C.R. Evaporation and deposition coverage area of droplets containing insecticides and spray additives on hydrophilic, hydrophobic and crabapple leaf surfaces. Trans. ASABE 2009, 52, 39-49. [CrossRef]

37. Xu, L.; Zhu, H.; Ozkan, E.; Bagley, W.E.; Derksen, R.C.; Krause, C.R. Adjuvant effects on evaporation time and wetted area of droplets on waxy leaves. Trans. ASABE 2010, 53, 13-20. [CrossRef] 
38. Zhu, H.; Yu, Y.; Ozkan, H.E.; Derksen, R.C.; Krause, C.R. Influence of Spray Additives on Droplet Evaporation and Residual Patterns on Wax and Wax-Free Surfaces; ASABE Paper, No. 083752; ASABE: St. Joseph, MI, USA, 2008. [CrossRef]

39. Gent, D.H.; Schwartz, H.F.; Nissen, S.J. Effect of commercial adjuvants on vegetable crop fungicide coverage, absorption, and efficacy. Plant Dis. 2003, 87, 591-597. [CrossRef]

40. ISO 10625:2018(en). Equipment for Crop Protection-Sprayer Nozzles—Colour Coding for Identification; The International Organization for Standardization: Geneva, Switzerland, 2018.

41. ISO 25358:2018(en). Crop Protection Equipment_Droplet-Size Spectra from Atomizers-Measurement and Classification; The International Organization for Standardization: Geneva, Switzerland, 2018.

42. Little, T.M. Interpretation and presentation of results. HortScience 1981, 16, 637-640.

43. Schechter, I.; Proctor, J.T.A.; Elfving, D.C. Morphological Differences among Apple Leaf Types. HortScience 1992, 27, 101-103. [CrossRef]

44. Eliáš, P. Stomata density and size of apple trees growing in irrigated and non irrigated conditions. Biologia 1995, 50, 115-118.

45. Skorupska, A. Morphologico-anatomical structure of leaves abd female fecundity of genus Tetranychus (Acarina, Tetranychidae) on selected scab-resistant apple varieties. J. Plant Prot. Res. 1999, 39, 144-152.

46. Hall, F.R.; Downer, R.A.; Cooper, J.A.; Ebert, T.A.; Ferree, D.C. Changes in Spray Retention by Apple Leaves during a Growing Season. HortScience 1997, 32, 858-860. [CrossRef]

47. Warabieda, W.; Solomon, M. Influence of leaf pubescence on the behavior of the two-spotted spider mite [Tetranychus urticae] and European red mite [Panonychus ulmi]. Acta Agrobot. 2003, 56, 109-115. [CrossRef]

48. Skorupska, A. Resistance of apple cultivars to two-spotted spider mite, Tetranychus urticae Koch (Acarina, Tetranychidae). Part II. Influence of leaf pubescence of selected apple cultivars on fecundity of two-spotted spider mite. J. Plant. Prot. Res. 2004, 44, 69-74.

49. Xu, L.; Zhu, H.; Ozkan, H.E.; Thistle, H.W. Evaporation rate and development of wetted area of water droplets with and without surfactant at different locations on waxy leaf surfaces. Biosyst. Eng. 2010, 106, 58-67. [CrossRef]

50. Zhu, H.; Yu, Y.; Ozkan, H.E.; Derksen, R.C.; Krause, C.R. Evaporation and wetted area of single droplets on waxy and hairy leaf surfaces. Commun. Agric. Appl. Biol. Sci. 2008, 73, 711-718. [PubMed]

51. Schönherr, J.; Baur, P.; Uhlig, B.A. Rates of cuticular penetration of 1-naphthylacetic acid (NAA) as affected by adjuvants, temperature, humidity and water quality. Plant. Growth Regul. 2000, 31, 61-74. [CrossRef] 